\title{
Metal Matrix Composites
}

\author{
Manoj Gupta
}

Materials Group, Department of Mechanical Engineering, National University of Singapore,

9 Engineering Drive 1, Singapore 117576, Singapore; mpegm@nus.edu.sg

Received: 21 May 2018; Accepted: 23 May 2018; Published: 24 May 2018

Metal Matrix Composites (MMCs) are a unique class of materials capable of providing design freedom to material scientists, allowing the creation of materials that can be targeted to a wide spectrum of applications [1,2]. The key factors that affect the design of MMCs include the following [1-3]:

(a) Choice of matrix material.

(b) Type, size (length scale) and amount of reinforcement.

(c) Type of processing (primary and secondary), as this controls the microstructure including matrix-reinforcement integrity.

(d) Heat treatment procedure.

The choice of matrix material and reinforcement is primarily influenced by the end application. For example, nickel-based materials are commonly chosen as matrices for high temperature applications, while titanium- and magnesium-based materials are considered for both light weighting of engineering structures and biomedical applications [1-5]. Similarly, different processing methods (primary and secondary) are chosen depending on many factors, such as cost of the end product, type of microstructure desired and volume of production. As an example, conventional casting is always preferred when high volume production is required. The proper utilization of heat treatment also plays a crucial role in selectively enhancing the properties of composites. In view of the dynamic scientific and application potential of metal matrix composites, the present thematic issue was launched and was highly successful, with 20 papers contributed by researchers from all over the world and accepted after rigorous peer review. Key materials that were investigated include the following:

(a) Aluminum-based materials.

(b) Magnesium-based materials.

(c) Titanium-based materials.

(d) Copper-based materials.

(e) Silver-based materials.

(f) Tungsten-based materials.

Reinforcement investigated in the above matrices included at least one of the following:

(a) $\mathrm{ZnO}$ in nanolength scale.

(b) $\mathrm{SiC}$ in nanolength scale.

(c) $\mathrm{Y}_{2} \mathrm{O}_{3}$ in nanolength scale.

(d) $\mathrm{Sm}_{2} \mathrm{O}_{3}$ in nanolength scale.

(e) Carbon-based reinforcements such as CNTs and graphene oxide.

(f) Metal-based reinforcement such as complex alloy reinforcement in micron length scale.

(g) Tungsten fiber nets.

(h) TiB.

(i) Intermetallic reinforcement such as $\mathrm{Mg}_{2} \mathrm{Si}$. 
(j) Saffil fibers.

(k) $\beta$-Tricalcium phosphate.

The types of processing that were employed to synthesize composites included the following:

(a) Liquid based methods such as the disintegrated melt deposition method including ultrasonication.

(b) Semi-solid or two-phase methods.

(c) In-situ method.

(d) Solid state method including cold and hot pressing, mechanical milling and spark plasma sintering.

(e) Thixoforging.

The reported properties of the metal matrix composites in this special issue included:

(a) Mechanical properties such as tensile and compression response.

(b) Ignition response.

(c) Damping response.

(d) Coefficients of thermal expansion.

(e) Elastic and plastic deformation behavior.

(f) Corrosion response.

The choice of matrix, reinforcement, processing method and characterization results reported by researchers in the twenty papers included in this special issue clearly indicate the prevalence of scientific curiosity and the optimism of researchers worldwide to create new metal-based composite materials for a wide range of applications, spanning from the biological sector to multiple engineering sectors.

This special issue certainly provides a succinct description of research activities conducted across the world and thus will be very useful for students and researchers in both academia and industry.

Finally, I would like to thank all the authors for their excellent contributions to this issue, to the reviewers for making useful comments, and to the Metals editorial staff for publishing these articles promptly.

Conflicts of Interest: The authors declare no conflict of interest.

\section{References}

1. Ibrahim, I.A.; Mohamed, F.A.; Lavernia, E.J. Particulate reinforced metal matrix composites-A review. J. Mater. Sci. 1991, 26, 1137-1156. [CrossRef]

2. Lloyd, D.J. Particle reinforced aluminium and magnesium matrix composites. Int. Mater. Rev. 1994, 39, 1-23. [CrossRef]

3. Ceschini, L.; Dahle, A.; Gupta, M.; Jarfors, A.E.W.; Jayalakshmi, S.; Morri, A.; Rotundo, F.; Toschi, S.; Singh, R.A. Aluminum and Magnesium Metal Matrix Nanocomposites; Springer: Singapore, 2016; ISBN 978-981-10-2680-5 (Print); 978-981-10-2681-2 (Online).

4. Gupta, M.; Seetharaman, S. Magnesium Based Nanocomposites for Cleaner Transport. In Nanotechnology for Energy Sustainability; Raj, B., Van de Voorde, M., Mahajan, Y., Eds.; Wiley-VCH: Weinheim, Germany, 2017.

5. Insight into Designing Biocompatible Magnesium Alloys and Composites; Gupta, M., Meenashisundaram, G.K., Eds.; Springer: Singapore, 2015. 